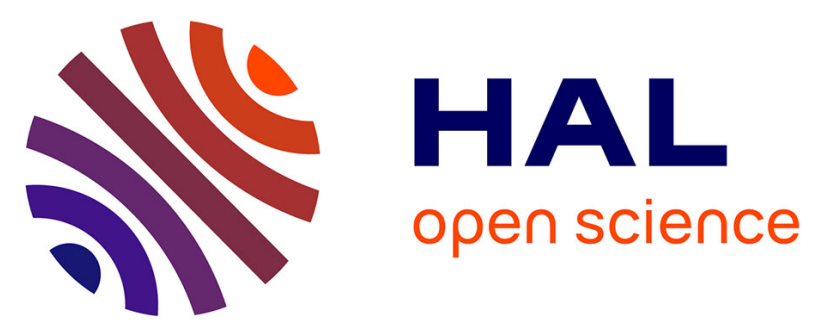

\title{
Cardiac troponin I elevation and overall survival among cancer patients receiving investigational compounds during phase I trials
}

Antoine Hollebecque, Emilie Lanoy, Frederic Troallen, Laurie Soulat-Dufour, Christophe Massard, Rastislav Bahleda, Andrea Varga, Anas Gazzah, Sophie Postel-Vinay, Vincent Ribrag, et al.

\section{To cite this version:}

Antoine Hollebecque, Emilie Lanoy, Frederic Troallen, Laurie Soulat-Dufour, Christophe Massard, et al.. Cardiac troponin I elevation and overall survival among cancer patients receiving investigational compounds during phase I trials. International Journal of Cardiology, 2016, 214, pp.364-369. 10.1016/j.ijcard.2016.04.010 . hal-01301384

\section{HAL Id: hal-01301384 https://hal.sorbonne-universite.fr/hal-01301384}

Submitted on 12 Apr 2016

HAL is a multi-disciplinary open access archive for the deposit and dissemination of scientific research documents, whether they are published or not. The documents may come from teaching and research institutions in France or abroad, or from public or private research centers.
L'archive ouverte pluridisciplinaire HAL, est destinée au dépôt et à la diffusion de documents scientifiques de niveau recherche, publiés ou non, émanant des établissements d'enseignement et de recherche français ou étrangers, des laboratoires publics ou privés. 


\section{Cardiac troponin I elevation and overall survival among cancer patients receiving investigational compounds during phase I trials}

Running title: Cardiac troponin I elevation in phase I cancer trials

Antoine Hollebecque ${ }^{a}$, Emilie Lanoy ${ }^{b}$, Frederic Troallen $^{c}$, Laurie Soulat-Dufour ${ }^{\mathrm{d}}$, Christophe Massard ${ }^{\mathrm{a}}$, Rastislav Bahleda ${ }^{\mathrm{a}}$, Andrea Varga ${ }^{\mathrm{a}}$, Anas Gazzah ${ }^{\mathrm{a}}$, Sophie Postel-Vinay ${ }^{\mathrm{a}, \mathrm{e}}$, Vincent Ribrag ${ }^{1}$, Eric Deutsch $^{\mathrm{a}, \mathrm{f},}$, Eric Angevin ${ }^{\mathrm{a}}$, Franck Boccara ${ }^{\mathrm{d}}$, Ariel Cohen ${ }^{\mathrm{d}}$, Jean-Charles Soria ${ }^{\mathrm{a}, \mathrm{e}}$, , Stephane Ederhy $^{* \mathrm{~d}^{\mathrm{d}}}$

${ }^{a}$ Drug Development Department (DITEP: Département d'Innovations Thérapeutiques et Essais Précoces), Gustave Roussy Cancer campus, 94805, Villejuif, France

${ }^{b}$ Service de biostatistique et épidémiologie, Gustave Roussy Cancer campus, 94805, Villejuif, France

${ }^{c}$ Département de biologie, Gustave Roussy Cancer campus, 94805, Villejuif, France

${ }^{d}$ Service de cardiologie, Hôpital Saint-Antoine, AP-HP, Université Pierre-et-Marie-Curie, ParisSorbonne 75012 Paris, France

${ }^{e}$ INSERM Unit U981, Gustave Roussy Cancer Campus, 94805, Villejuif, France

${ }^{f}$ Département de radiothérapie, Gustave Roussy Cancer campus, 94805, Villejuif, France

\section{${ }^{*}$ Corresponding author at:}

Service de cardiologie, Hôpital Saint Antoine, 184 rue du Faubourg Saint Antoine 75012 Paris, France.

Tel: 0033149282503

Fax: 0033749282128

E-mail address: stephane.ederhy@aphp.fr

All authors take responsibility for all aspects of the reliability and freedom from bias of the data presented and their discussed interpretation. 


\section{ABSTRACT}

Objective: To identify factors associated with troponin elevation and to measure the effect of elevated troponin on survival in cancer patients participating in phase I trials.

Methods: Clinical characteristics, cardiovascular risk factors, and biological data from consecutive patients treated in phase I trials (January 2010-November 2012) were reviewed. Troponin value was measured for each patient before study-drug administration and then weekly. Cardiac troponin I was considered elevated if $>0.06 \mathrm{ng} / \mathrm{mL}$. Incidence and relative risk of elevated troponin adjusted for potential confounding factors were estimated using multivariable Poisson regression models. A conditional Cox proportional hazards model was used to compare overall survival in patients with elevated troponin matched to patients without troponin elevation recruited in the same trial.

Results: Of 463 patients, 42 (9\%) experienced $\geq 1$ episode of troponin I elevation after a median of 5 weeks (interquartile range: 3-13) from drug initiation. Crude incidence of troponin elevation was 36/1000 person-months (95\% confidence interval [CI]: 25-47). Troponin elevation was more frequent in patients exposed to antiangiogenic compounds versus other treatments (relative risk: $1.9,95 \% \mathrm{Cl}$ : 1.1-3.3). Median overall survival from drug initiation was 9 months (95\% Cl: $8-10)$, and 8 months (95\% Cl: 2-13) in patients with troponin elevation. In the case-control analysis, risk of death was higher in patients with troponin elevation (hazard ratio: $2.9,95 \% \mathrm{Cl}: 1.2-6.8$ ).

Conclusion: Patients exposed to antiangiogenic compounds had a higher risk of troponin elevation, which was associated with a higher risk of death.

Keywords: Troponin, Cardio oncology, Cardiotoxicity, Phase I trial, Drug development 


\section{Introduction}

The evaluation of cardiovascular safety is an important step in the development of new treatments for cancer [1]. In phase I trials, cardiovascular evaluation is frequently mandated by protocol and is based on clinical examination, QT measurement, left ventricular systolic function, and biomarker measurement [2]. B-type natriuretic peptide and troponin play an important role in the evaluation of cardiotoxicity [3]. Troponin is a marker of myonecrosis and was first validated as a diagnostic and prognostic marker in patients with suspected acute coronary syndromes [4]. In the context of patients with cancer, cardiac troponin was proposed as an indicator of cardiotoxicity related to cancer treatments [5]. Elevated troponin has also been reported in patients treated with moleculartargeted drugs [6], but the incidence, mechanisms, and prognostic significance of a troponin rise in patients with cancer are unknown [7]. In this study, we investigated the incidence of and risk factors associated with troponin elevation, and its effect on overall survival.

\section{Methods}

\subsection{Patients}

Clinical, biological, and therapeutic data from patients treated in phase I trials between January 2010 and November 2012 at the Drug Development Department (DITEP) of Gustave Roussy Cancer campus were reviewed. Patients with a history or current condition of uncontrolled cardiovascular disease including unstable angina, myocardial infarction, or congestive heart failure class II-IV within the preceding 12 months, cerebrovascular accident, transient ischemic attack within the preceding 6 months, pulmonary embolism within the preceding 3 months, and patients presenting a QTc prolongation (Fridericia; QTc >450 milliseconds in men or $>470$ milliseconds in women) were excluded from the phase I trials and thus from this analysis.

Patients were eligible for this analysis if they had at least one cardiac troponin I (cTnl) measurement taken before study-drug initiation and if they had a subsequent repeat troponin evaluation during the trial. Patients with a troponin measurement $>0.06 \mathrm{ng} / \mathrm{mL}$ during the screening period were excluded from the analysis. If a patient had been successively recruited in different phase I trials, only the first trial in which the patient participated was considered. The study was approved by the local ethics committee. 


\subsection{Cardiac troponin I measurement}

During the screening period, cTnl was evaluated for each patient and then at each visit, which was planned on a weekly basis until the end of the clinical trial.

cTnl was measured in blood serum samples using the same immunoassay system (BeckmanCoulter, Fullerton, USA) with the AccuTnI ${ }^{\odot}$ (ref A78803) assay and AccuTnI ${ }^{\odot}$ (ref 33345) calibrators. Both external and internal quality controls were used to verify the accuracy of the results. The 99th percentile cut-off value of cTnl (from a healthy reference population) was set at $0.06 \mathrm{ng} / \mathrm{mL}$.

\subsection{Statistical analysis}

For each patient, cardiovascular risk factors, and clinical and biological data were recorded and reviewed. Phase I drugs were categorized according to their mechanism of action. To identify factors associated with troponin elevation, the incidence and relative risk of troponin elevation according to clinical characteristics were estimated using univariable Poisson regression models. All variables with a $p$-value of $<0.20$ were entered in a multivariable Poisson model. The final model was retained using a backward procedure, including variables with a $p$-value of $<0.05$. To estimate the effect of troponin elevation on survival, a matched case-control design was used. One patient with troponin elevation after $\mathrm{x}$ weeks of treatment was matched with one patient without troponin elevation after $\mathrm{x}$ weeks of treatment (control) recruited in the same protocol. Matching was performed with replacement.

In the overall survival analysis, patients were followed from the week of troponin elevation (cases) or the week of troponin elevation in the matched case (controls) to death or to the end of follow-up. Overall survival from troponin elevation was estimated using the Kaplan-Meier method. A Cox proportional hazards model stratified on matched pairs was used to assess the effect of troponin elevation on overall survival adjusted for age, sex, body mass index, history of hypertension, history of hypercholesterolemia, and human epidermal growth factor receptor 2 (HER2) inhibitor treatment. All variables with a $p$-value of $<0.20$ were entered in a model, and a backward procedure retaining variables with a $p$-value of $<0.05$ was used to select the best model.

All analyses were done using SAS 9.3 software (SAS Institute, Cary, North Carolina). 


\section{Results}

\subsection{Patient baseline characteristics}

Overall, 649 consecutive patients were recruited in the phase I trials, of which 499 patients had at least one troponin evaluation before study-drug initiation. Thirty-two patients were secondarily excluded because they had a history of troponin elevation at the screening evaluation and four because of missing data. The study population therefore comprised 463 patients (Fig. 1), who had been treated for a total of 1159 months. Most patients (95\%) had metastatic disease; the remaining $5 \%$ had locally advanced cancer.

The median age of the study population was 57 years (interquartile range [IQR]: 49-64 years), the median body mass index was $24 \mathrm{~kg} / \mathrm{m}^{2}$ (IQR: 22-26), and median fibrinogen concentration was $4.8 \mathrm{~g} / \mathrm{L}$ (IQR: 3.8-6.1). Seventy-eight patients (17\%) had a history of hypertension, 28 patients (6\%) had a history of diabetes, and 28 patients $(6 \%)$ had a history of dyslipidemia. The median number of previous lines of treatment was 2 (IQR: $0-2)$. Molecular-targeted agents and compounds administered during the phase I trials and their main mechanisms of action are detailed in Table 1.

\subsection{Incidence of troponin elevation}

During phase I drug exposure, troponin elevation occurred in 42 (9\%) patients. The crude incidence was 36/1000 person-months (95\% confidence interval [CI]: 25-47). The median delay between drug introduction and troponin elevation was 5 weeks (IQR: 3-13) and the median elevated troponin concentration was $0.12 \mathrm{ng} / \mathrm{mL}$ (IQR: 0.10-0.15). Among the 42 patients with elevated troponin, the elevation was transient in $29(69 \%)$ patients, persistent in $4(10 \%)$ patients, and diagnosed from the last available troponin measurement with no further values in 9 (21\%) patients. When considering higher cut-offs for troponin elevation, the incidence of troponin $>0.12 \mathrm{ng} / \mathrm{mL}$ was 11/1000 person-months (95\% Cl: $5-17)$ and for $>0.15 \mathrm{ng} / \mathrm{mL}$ was $9 / 1000$ person-months $(95 \% \mathrm{Cl}$ : $2-$ 14).

None of the patients who had elevated troponin elevation had symptoms suggesting acute coronary syndrome, electrocardiographic changes, or a decrease in left ventricular ejection fraction $>5$ units compared with baseline (data not shown). 
Coronary angiography was performed in 32 patients. No cases of coronary occlusion or coronary artery stenosis $>70 \%$ were found. Pulmonary embolism was ruled out using computed tomography scanning in 28 of the 42 patients with elevated troponin.

\subsection{Risk factors for troponin elevation during phase I trials}

The incidence of elevated troponin according to the patients' baseline characteristics and phase I treatment is described in Table 2. In univariate analysis, antiangiogenic drugs and fibrinogen elevation $\geq 6 \mathrm{~g} / \mathrm{L}$ were associated with troponin elevation, whereas sex, age, body mass index, history of diabetes, hypertension, hypercholesterolemia, and use of HER2 inhibitors were not. The relative risk of troponin elevation was $1.9(95 \% \mathrm{Cl}: 1.1-3.3 ; \mathrm{p}=0.01)$ when patients received an antiangiogenic agent during the phase I trials. Fibrinogen concentration $\geq 6 \mathrm{~g} / \mathrm{L}$ was associated with a relative risk of troponin elevation of 1.9 (95\% Cl: $0.95-3.6 ; p=0.035)$ whereas fibrinogen values between $4 \mathrm{~g} / \mathrm{L}$ and 6 $\mathrm{g} / \mathrm{L}$ were not (relative risk: $0.89,95 \% \mathrm{Cl}: 0.44-1.8)$. In multivariable analysis, the use of antiangiogenic drugs was the only independent predictive predictor of troponin elevation. The incidence of elevated troponin was 60/1000 person-months (95\% Cl: 35-85) in patients exposed to an angiogenesis inhibitor.

\subsection{Prognosis value of troponin elevation}

The median overall survival of the 463 patients included in the analysis was 9 months (95\% $\mathrm{Cl}: 8-10)$. In the 42 patients with elevated troponin, the median overall survival after troponin elevation was 8 months (95\% Cl: $2-13)$.

In the case-control analysis, 42 patients who experienced a troponin elevation were matched for age with 36 controls (Table 3). The risk of death was higher in patients who experienced troponin elevation (Fig. 2) with a hazard ratio for death of 2.9 (95\% Cl: 1.2-6.8).

\section{Discussion}

The three mains findings of this study, involving patients with cancer participating in phase I trials, are as follows. First, $9 \%$ of patients experienced a troponin elevation, defined as a value $>0.06$ $\mathrm{ng} / \mathrm{mL}$. Second, the use of antiangiogenic agents - and not cardiovascular risk factors - was 
significantly associated with troponin elevation and was the main predictor of troponin rise. Third, a slight rise in troponin was associated with a poor outcome and an increased risk of death.

The recent introduction of molecular-targeted agents has led to a significant improvement in the management and treatment of solid tumors with a poor prognosis [8]. However, their use is associated with several unexpected and undesirable cardiac and vascular side-effects, including left ventricular systolic dysfunction and hypertension, considered "on-target" side-effects, and QT interval prolongation, considered an "off-target" side-effect $[9,10]$. Troponin rise in patients receiving a chemotherapy regimen containing anthracycline or trastuzumab is associated with left ventricular systolic dysfunction and adverse cardiac events $[5,6]$. We extend these findings, showing that antiangiogenic agents are potentially associated with troponin elevation [9].

We did not find any association between troponin rise and left ventricular systolic dysfunction in our study. Several potentials explanations could be proposed. First, our study was not designed to study the link between troponin elevation and left ventricular systolic dysfunction. Not all of the patients in our cohort were explored with echocardiography at baseline and during the course of the phase I trial. All patients were fully evaluated at the time of troponin rise, including echocardiography in all patients and coronary angiography in some patients. We used conventional troponin, which could have limited our ability to detect a slight rise in troponin and thus cardiotoxicity. The total duration of follow-up was relatively short due to the advanced stage of cancer in our patients; this factor may have limited our ability to detect a link between slight troponin elevation and left ventricular systolic dysfunction that could occur later after administration of the cardiotoxic chemotherapy. Finally, it could be hypothesized that the mechanism implicated in troponin rise due to an angiogenic agent is different from anthracycline or trastuzumab and does not lead in all cases to left ventricular systolic dysfunction

The mechanism underlying a slight troponin rise in the context of anticancer therapy remains poorly understood and probably differs according to the study drug used. In patients receiving anthracycline, it has been postulated that troponin rise is due to the generation of reactive oxygen species [10]. In patients receiving HER2, the mechanisms are not fully understood [6]. In a murine model, Chu et al. found that cardiotoxicity associated with sunitinib was due to mitochondrial injury without apoptosis or fibrosis [10]. 
In phase I trials, the frequency, mechanisms, and the prognostic significance of troponin elevation remains largely unknown, and is insufficiently described and understood. We have previously shown that patients receiving molecular-targeted agents are prone to develop a troponin rise and that the mechanisms underlying troponin elevation are not associated with coronary occlusion or myocarditis [7]. In the present study we found that $9 \%$ of the cohort exhibited a slight troponin rise, and this was associated with important prognostic implications.

The spontaneous prognosis of patients in phase I trials remains poor despite having a good performance status at study entry [11]. Several models have been developed to predict mortality; demographic variables (functional status), oncologic variables (number of metastases), and biological factors (lactate dehydrogenase, white blood cells) are robust predictors of mortality in phase I trials [12]. Recent studies demonstrated that cardiac biomarkers are elevated in patients with cancer and are related to all-cause mortality as well as alteration of echocardiographic variables $[13,14]$. These results, in conjunction with ours, suggest that cardiac involvement in patients with cancer evaluated with biomarkers or by echocardiography could be considered as a potential marker of overall survival and disease progression, and not only as a marker of cardiotoxicity.

\subsection{Limitations}

Our study has several limitations. Our study was restricted to conventional troponin only, and did not include high-sensitivity troponin or other biomarkers. The specific cause of death in our cohort could not be addressed precisely in approximately $65 \%$ of patients, and cardiovascular events could not be identified or well characterized. Pulmonary embolism was not systematically ruled out and coronary angiography was not performed in all patients with a troponin rise.

In conclusion, troponin elevation is a relatively frequent event among patients with cancer participating in phase I trials. Patients exposed to antiangiogenic drugs present a higher risk of a rise in cardiac troponin, which is associated with a higher risk of death. The results of our study suggest that patients presenting with troponin elevation deserve closer clinical and cardiologic follow-up. 


\section{Source of funding}

None received. This study was conducted independently of any industry or other grant support.

\section{Disclosure of conflicts of interest}

All authors had full access to all of the data in this study and take responsibility for the integrity of the data and the accuracy of the data analysis. All authors contributed to the design, analysis, interpretation of data, drafting the article, or revising it critically for important intellectual content and approved the final version to be published.

\section{Acknowledgements}

Sophie Rushton-Smith, PhD, provided editorial assistance on the last version of the article and was funded by the authors. 


\section{References}

[1] Postel-Vinay S, Collette L, Paoletti X, Rizzo E, Massard C, Olmos D, et al. Towards new methods for the determination of dose limiting toxicities and the assessment of the recommended dose for further studies of molecularly targeted agents--dose-Limiting Toxicity and Toxicity Assessment Recommendation Group for Early Trials of Targeted therapies, an European Organisation for Research and Treatment of Cancer-led study. Eur J Cancer. 2014;50:2040-9.

[2] Johnson CB, Sulpher J, Stadnick E. Evaluation, prevention and management of cancer therapyinduced cardiotoxicity: a contemporary approach for clinicians. Curr Opin Cardiol. 2015.

[3] Ky B, Putt M, Sawaya H, French B, Januzzi JL, Jr., Sebag IA, et al. Early increases in multiple biomarkers predict subsequent cardiotoxicity in patients with breast cancer treated with doxorubicin, taxanes, and trastuzumab. J Am Coll Cardiol. 2014;63:809-16.

[4] Thygesen K, Alpert JS, Jaffe AS, Simoons ML, Chaitman BR, White HD, et al. Third universal definition of myocardial infarction. Circulation. 2012;126:2020-35.

[5] Plana JC, Galderisi M, Barac A, Ewer MS, Ky B, Scherrer-Crosbie M, et al. Expert consensus for multimodality imaging evaluation of adult patients during and after cancer therapy: a report from the American Society of Echocardiography and the European Association of Cardiovascular Imaging. J Am Soc Echocardiogr. 2014;27:911-39.

[6] Cardinale D, Colombo A, Torrisi R, Sandri MT, Civelli M, Salvatici M, et al. Trastuzumab-induced cardiotoxicity: clinical and prognostic implications of troponin I evaluation. J Clin Oncol. 2010;28:39106.

[7] Ederhy S, Massard C, Dufaitre G, Balheda R, Meuleman C, Rocca CG, et al. Frequency and management of troponin I elevation in patients treated with molecular targeted therapies in phase I trials. Invest New Drugs. 2012;30:611-5.

[8] Wang Z, Dabrosin C, Yin X, Fuster MM, Arreola A, Rathmell WK, et al. Broad targeting of angiogenesis for cancer prevention and therapy. Semin Cancer Biol. 2015;35 Suppl:S224-43. [9] Schmidinger M, Zielinski CC, VogI UM, Bojic A, Bojic M, Schukro C, et al. Cardiac toxicity of sunitinib and sorafenib in patients with metastatic renal cell carcinoma. J Clin Oncol. 2008;26:5204-12. [10] Chu TF, Rupnick MA, Kerkela R, Dallabrida SM, Zurakowski D, Nguyen L, et al. Cardiotoxicity associated with tyrosine kinase inhibitor sunitinib. Lancet. 2007;370:2011-9. 
[11] Ploquin A, Olmos D, Ferte C, Cassier PA, Kramar A, Duhamel A, et al. Life-expectancy of patients enrolled in phase 1 clinical trials: a systematic review of published prognostic models. Crit Rev Oncol Hematol. 2012;83:242-8.

[12] Olmos D, A'Hern R P, Marsoni S, Morales R, Gomez-Roca C, Verweij J, et al. Patient selection for oncology phase I trials: a multi-institutional study of prognostic factors. J Clin Oncol. 2012;30:9961004.

[13] Pavo N, Raderer M, Hulsmann M, Neuhold S, Adlbrecht C, Strunk G, et al. Cardiovascular biomarkers in patients with cancer and their association with all-cause mortality. Heart. $2015 ; 101: 1874-80$.

[14] Rhea IB, Uppuluri S, Sawada S, Schneider BP, Feigenbaum H. Incremental prognostic value of echocardiographic strain and its association with mortality in cancer patients. J Am Soc Echocardiogr. 2015;28:667-73. 


\section{Legends}

Fig. 1. Patient flow chart.

Fig. 2. Overall survival according to troponin elevation (matched population). 


\section{Table 1}

Mechanism of treatment and occurrence of troponin $>0.06 \mathrm{ng} / \mathrm{mL}$ (1 line per therapy).

\begin{tabular}{|c|c|c|c|}
\hline & $\mathrm{N}(\%)$ & $\begin{array}{l}\text { Patient-months on } \\
\text { phase I drug } \\
\text { treatment }\end{array}$ & $\begin{array}{l}\text { Incident case of } \\
\text { troponin elevation while } \\
\text { on phase I therapy }\end{array}$ \\
\hline & & Sum & \\
\hline All & $843(100)$ & 2130 & 81 \\
\hline \multicolumn{4}{|l|}{ Mechanism of experimental therapy } \\
\hline Adhesion & $7(1)$ & 12 & 1 \\
\hline Angiogenesis inhibition & $114(14)$ & 367 & 22 \\
\hline Anti-hormonal therapy & $7(1)$ & 25 & 0 \\
\hline Cell cycle & $53(6)$ & 112 & 2 \\
\hline Cytotoxic & $134(16)$ & 391 & 18 \\
\hline $\begin{array}{l}\text { Fibroblast growth factor pathway } \\
\text { inhibition }\end{array}$ & $4(0.5)$ & 7 & 0 \\
\hline HER2 inhibition & $95(11)$ & 237 & 6 \\
\hline Immune therapy & $7(1)$ & 9 & 0 \\
\hline MAP kinase & $17(2)$ & 57 & 3 \\
\hline PIK3/Akt/mTOR & $80(9)$ & 224 & 7 \\
\hline Radiotherapy & $61(7)$ & 116 & 4 \\
\hline Transversal process inhibition & 207 (25) & 458 & 17 \\
\hline
\end{tabular}

Abbreviations: HER2 = human epidermal growth factor receptor 2; MAP = mitogen-activated protein kinase; PIK = phosphatidylinositol-4,5-bisphosphate 3-kinase. 


\section{Table 2}

Incidence of troponin elevation under phase I treatment according to baseline characteristics at phase I drug initiation.

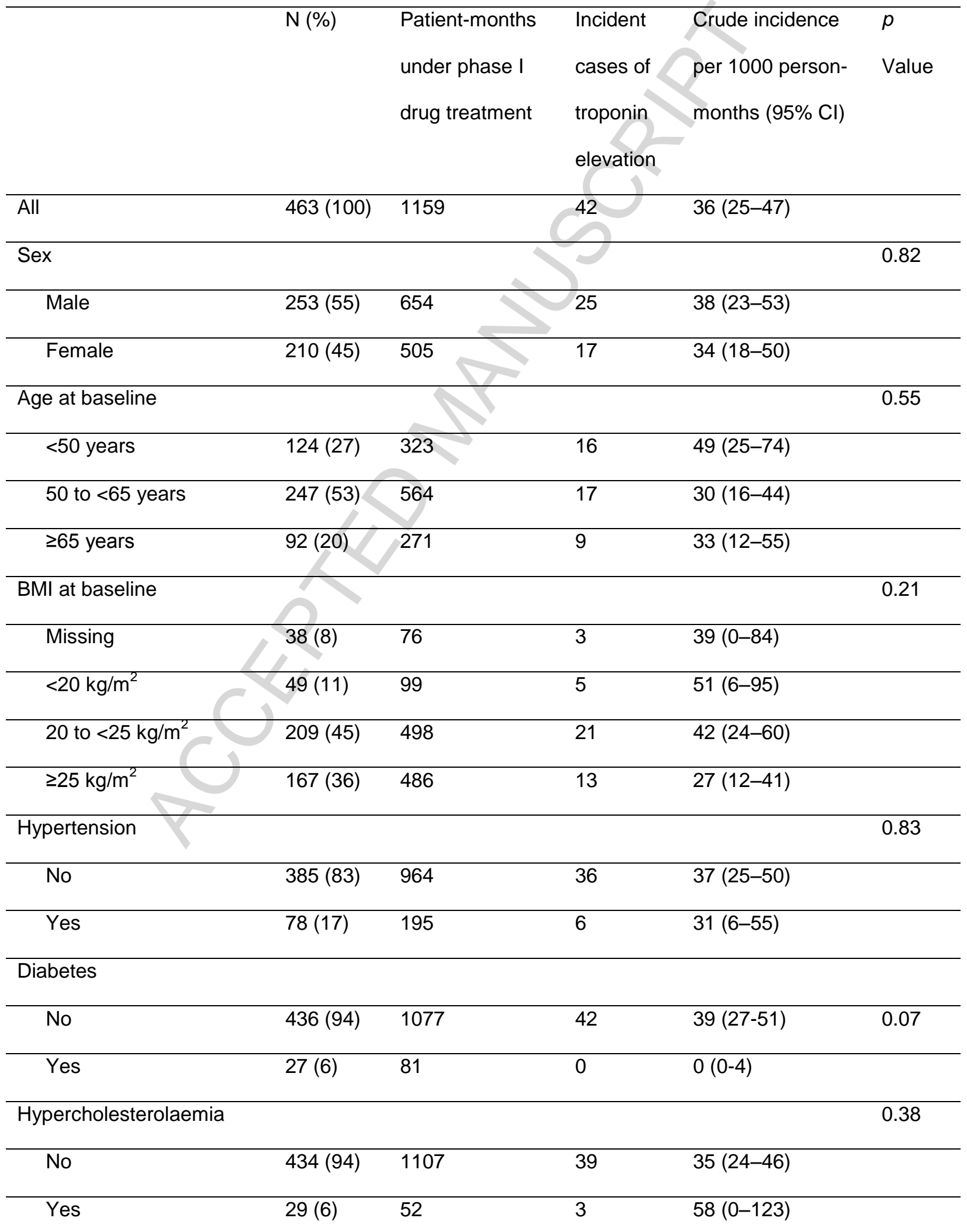




\begin{tabular}{|c|c|c|c|c|}
\hline Fibrinogen at baseline & & & & 0.04 \\
\hline Missing & $44(10)$ & 111 & $18(0-43)$ & \\
\hline$<4 \mathrm{~g} / \mathrm{L}$ & $114(25)$ & 312 & $32(12-52)$ & \\
\hline 4 to $6 \mathrm{~g} / \mathrm{L}$ & $193(42)$ & 471 & $32(16-48)$ & \\
\hline$\geq 6 \mathrm{~g} / \mathrm{L}$ & $112(24)$ & 264 & $57(28-85)$ & \\
\hline \multicolumn{5}{|l|}{ Angiogenesis inhibition } \\
\hline No & $366(79)$ & 888 & $29(18-41)$ & 0.015 \\
\hline Yes & $97(21)$ & 271 & $60(35-85)$ & \\
\hline HER2 inhibition & & & & 0.89 \\
\hline No & $401(87)$ & 975 & $40(27-53)$ & \\
\hline Yes & $62(13)$ & 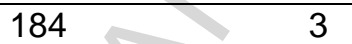 & $25(5-46)$ & \\
\hline
\end{tabular}

Abbreviations: BMI = body mass index; HER2 = human epidermal growth factor receptor 2 . 


\section{Table 3}

Description of patients included and not included in the matched case-control analysis.

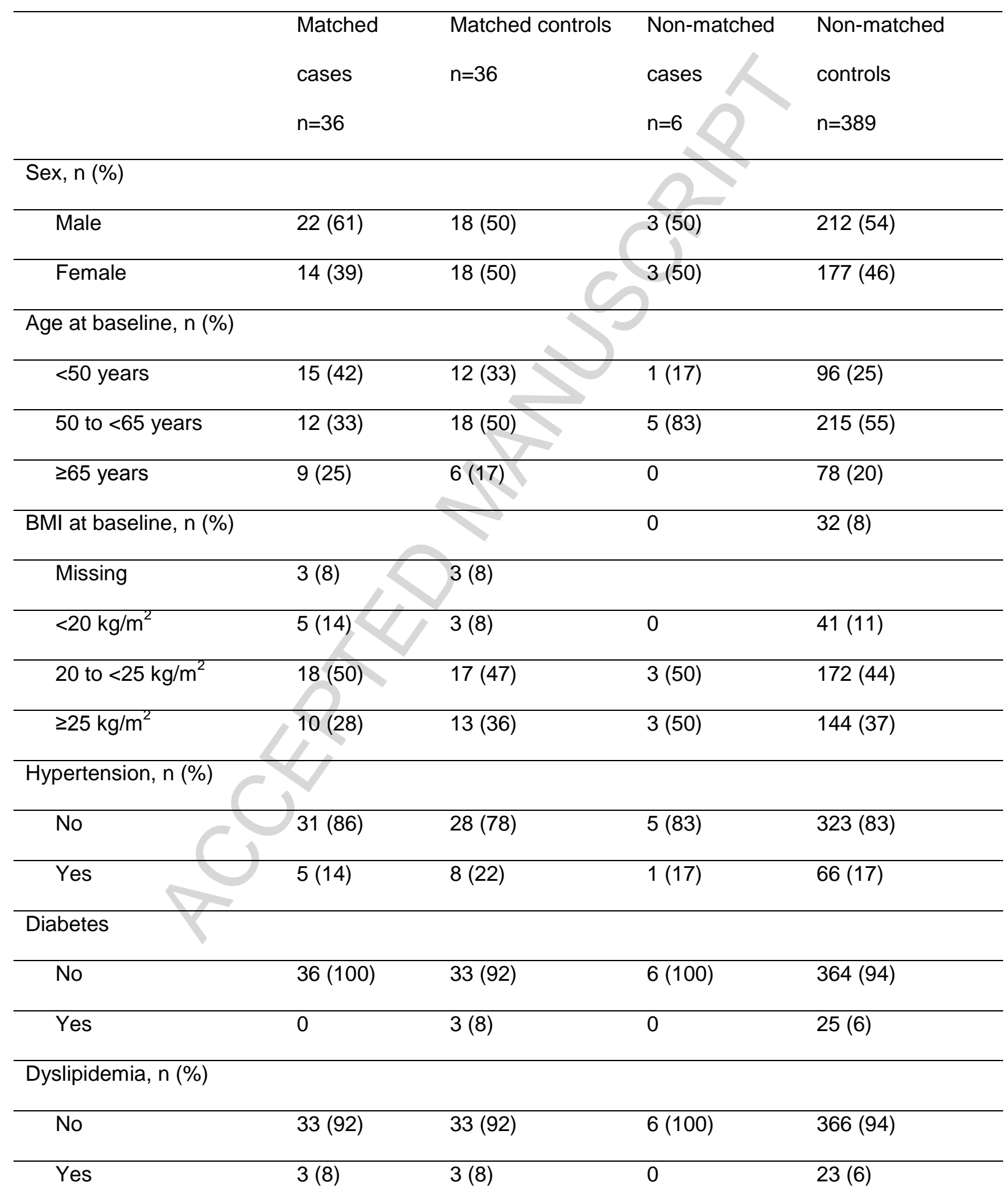

Fibrinogen at baseline, $\mathrm{n}$

(\%)

$\begin{array}{lllll}\text { Missing } & 2(6) & 4(11) & 0 & 38(10)\end{array}$




\begin{tabular}{lcccc}
\hline$<4 \mathrm{~g} / \mathrm{L}$ & $7(19)$ & $11(31)$ & $3(50)$ & $93(24)$ \\
\hline 4 to $6 \mathrm{~g} / \mathrm{L}$ & $13(36)$ & $16(44)$ & $2(33)$ & $165(42)$ \\
\hline$\geq 6 \mathrm{~g} / \mathrm{L}$ & $14(39)$ & $5(14)$ & $1(17)$ & $93(24)$
\end{tabular}

Angiogenesis inhibition, $\mathrm{n}$

$(\%)$

\begin{tabular}{ccccc}
\hline No & $21(58)$ & $21(58)$ & $5(83)$ & $319(82)$ \\
\hline Yes & $15(42)$ & $15(42)$ & $1(17)$ & $70(18)$ \\
\hline HER2 inhibition, $\mathrm{n}(\%)$ & & & & \\
\hline No & $34(94)$ & $34(94)$ & $5(83)$ & $332(85)$ \\
\hline Yes & $2(6)$ & $2(6)$ & $1(17)$ & $57(15)$
\end{tabular}

Cause of death, $\mathrm{n}(\%)$

\begin{tabular}{llccc}
\hline Missing & $9(25)$ & $20(56)$ & $4(67)$ & $186(48)$ \\
\hline Progression & $12(33)$ & $12(33)$ & $1(17)$ & $131(34)$ \\
\hline Unknown & $15(42)$ & $4(11)$ & $1(17)$ & $70(18)$ \\
\hline Other cause & 0 & 0 & 0 & $2(1)$
\end{tabular}

Abbreviations: BMI = body mass index; HER2 = human epidermal growth factor receptor 2 .

Total number is $467>463$ because same control could be matched with different cases: one control was selected three times and two controls were selected twice. 


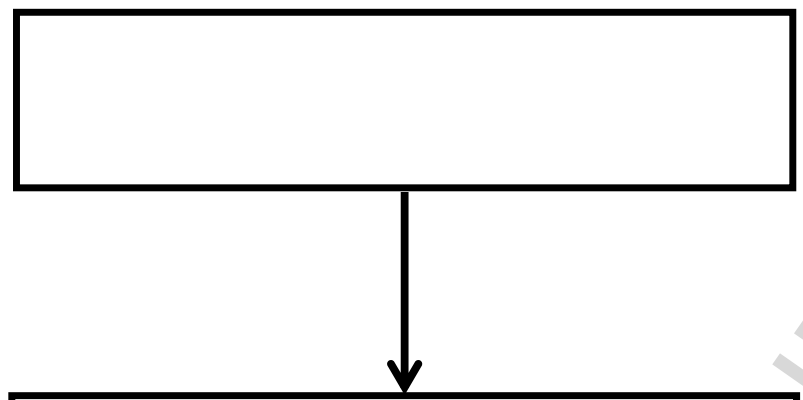

499 patients with at least 1 troponin value in the

30 days before phase I drug initiation and at least 1 treatment after

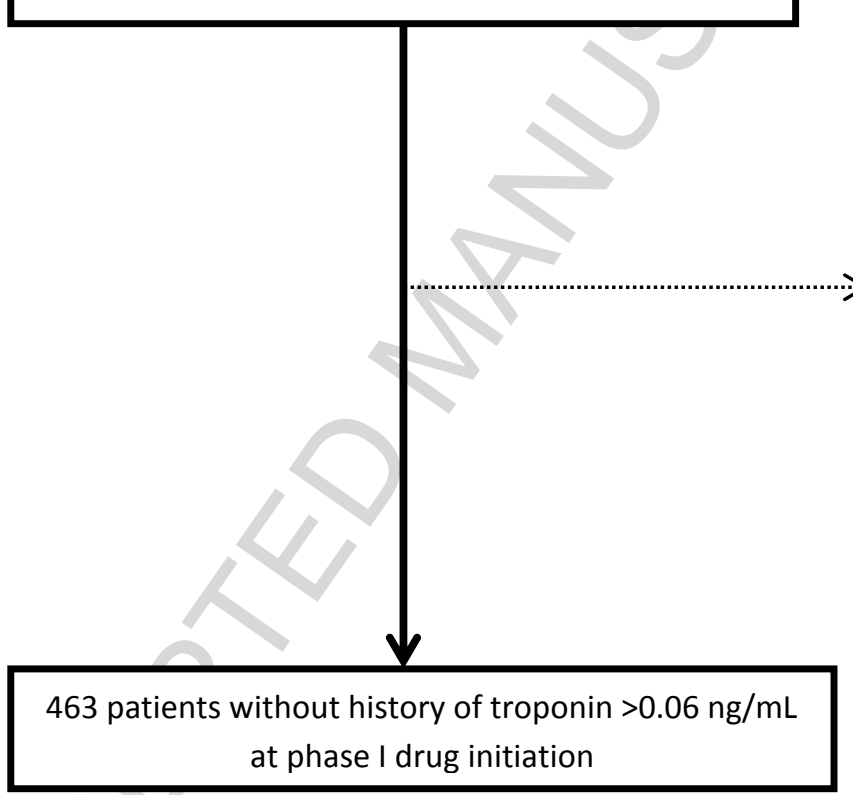

32 patients with a history of troponin elevation before phase I drug initiation

4 patients with missing data

Figure 1 


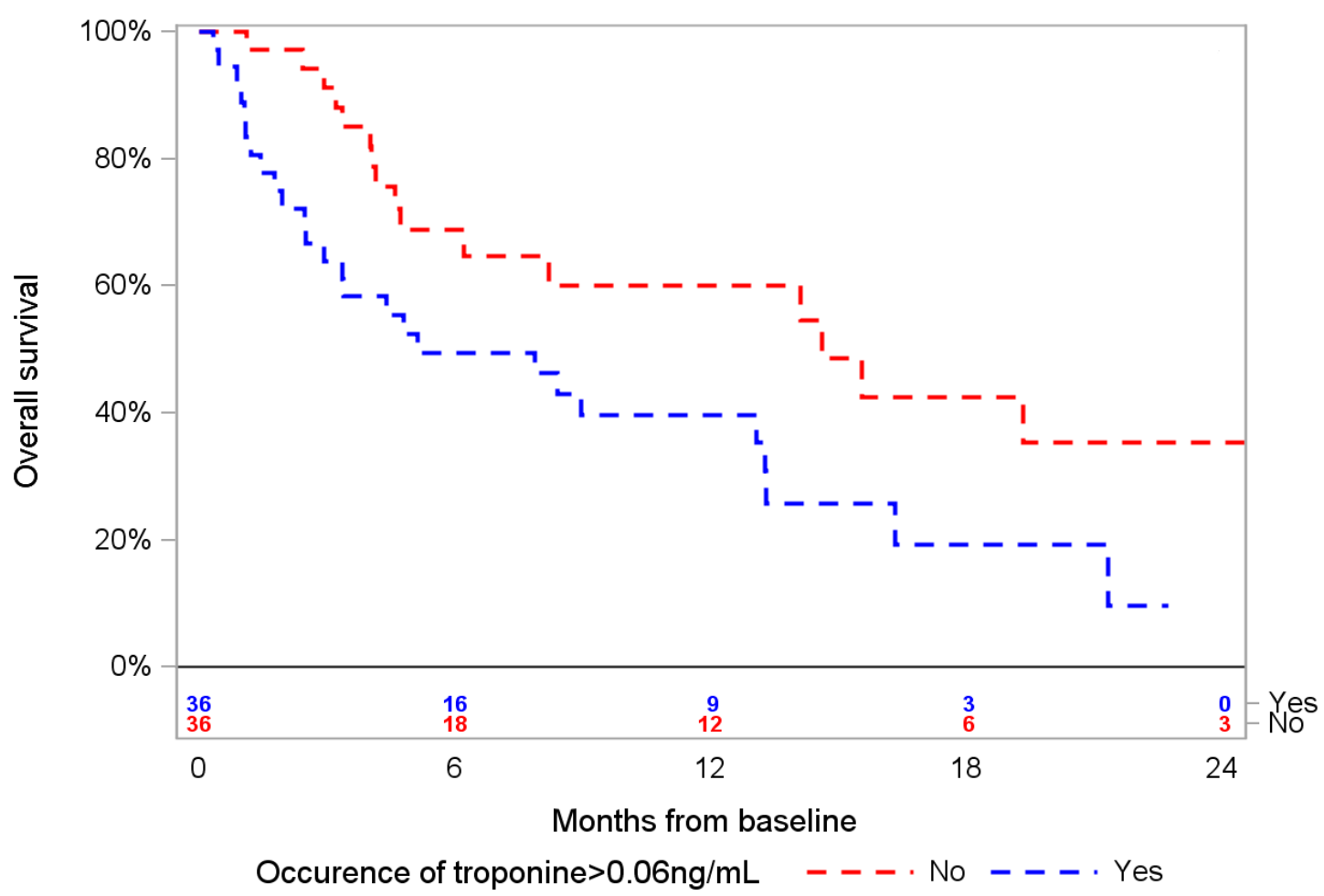

Figure 2 